Review

\title{
Review: In situ and bioremediation of organic pollutants in aquatic sediments
}

\author{
Louisa Wessels Perelo* \\ Departamento de Engenharia Ambiental, Escola Politécnica, Universidade Federal da Bahia, Rua Prof. Aristides Novis, 02 - Federação, CEP: 40210-910, Salvador, BA, Brazil
}

\section{A R T I C L E I N F O}

\section{Article history:}

Received 15 August 2009

Received in revised form 1 December 2009

Accepted 18 December 2009

Available online 29 December 2009

\section{Keywords:}

Sediment

Organic pollutants

Remediation technologies

Bioremediation

\begin{abstract}
A B S T R A C T
Organic pollutants in sediments are a worldwide problem because sediments act as sinks for hydrophobic, recalcitrant and hazardous compounds. Depending on biogeochemical processes these hydrocarbons are involved in adsorption, desorption and transformation processes and can be made available to benthic organisms as well as organisms in the water column through the sediment-water interface. Most of these recalcitrant hydrocarbons are toxic and carcinogenic, they may enter the food-chain and accumulate in biological tissue. Several approaches are being investigated or have been already used to remove organic hydrocarbons from sediments. This paper provides a review on types and sources of organic pollutants as well as their behavior in sediments. It presents the advantages and disadvantages of traditional sediment remediation techniques in use, such as dredging, capping and monitored natural attenuation. Furthermore, it describes new approaches with emphasis on bioremediation, like biostimulation, bioaugmentation and phytoremediation applied to sediments. These new techniques promise to be of lower impact and more cost efficient than traditional management strategies.
\end{abstract}

(c) 2009 Published by Elsevier B.V.

\section{Contents}

1. Introduction.

2. Organic pollutants .

2.1. Polycyclic aromatic hydrocarbons (PAHs) .

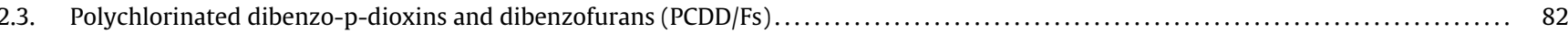

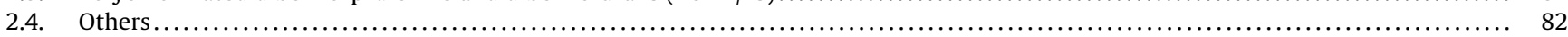

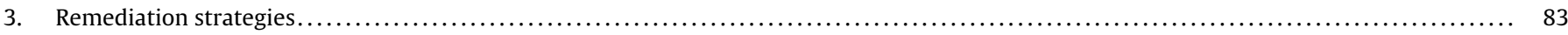

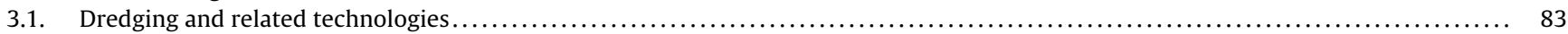

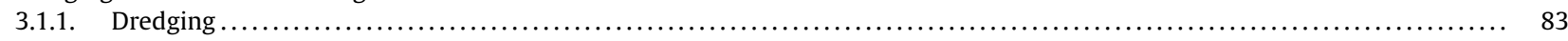

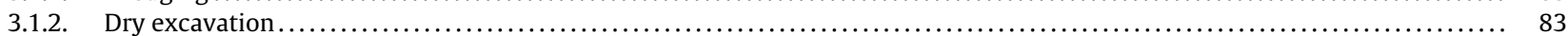

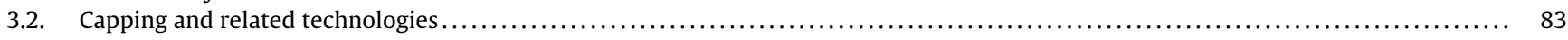

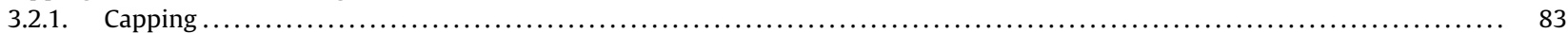

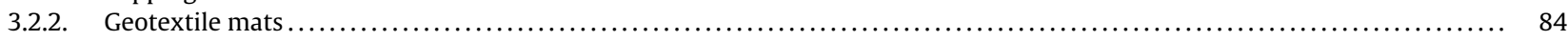

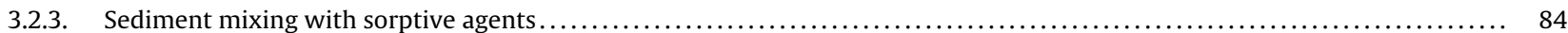

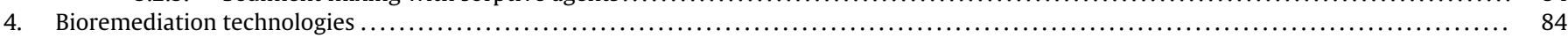

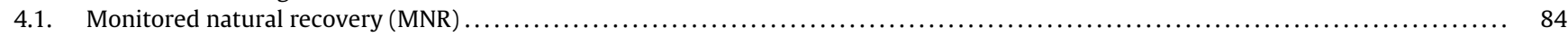

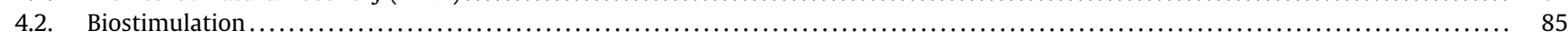

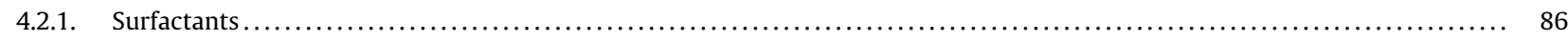

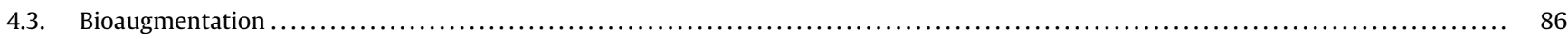

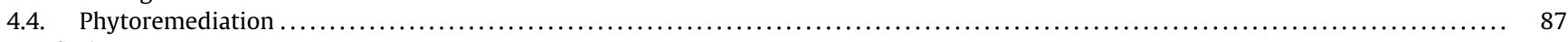

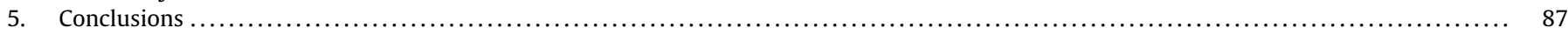

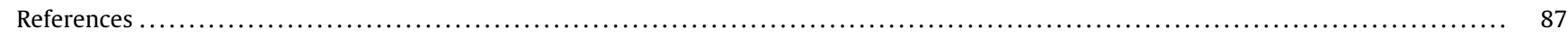

\footnotetext{
* Tel.: +55 71 32839780; fax: +55 7132839780 .

E-mail address: louisa@ufba.br.
}

\section{Introduction}

Aquatic sediments are repositories of physical and biological debris and act as sinks for a wide variety of organic and inorganic pollutants [1]. Chemical contaminants present in the aquatic 
ecosystem may be immobilized and accumulated in sediments or may be subject to transformation and activation processes [2].

Contrary to inorganic pollutants, such as heavy metals, hydrocarbons can be transformed and degraded mainly by biological processes, with degradation resulting sometimes to mineralization. Aquatic sediments, because of their inherently anaerobic conditions and abundant carbon and energy sources, tend to have ample microbial biomass and diversity [3], which are potentially able to degrade organic pollutants.

Hydrocarbons may enter the aquatic ecosystem either directly, by effluents or spills, or indirectly by terrestrial runoff or atmospheric deposition. Their persistence in the environment depends mainly on their chemical and physical characteristics. The more complex their structure, the more halogenated and hydrophobic they are, the more these pollutants tend to accumulate in sediments associated to particulate material therein.

Hydrocarbons can become dangerous especially if they enter the food-chain, since several of the more persistent compounds, as PAHs and PCBs are carcinogenic [4].

In the sediments, organic pollutants may associate temporarily to the particulate matter, establishing equilibrium relations in the water-sediment interface. These sorption and desorption processes substantially determine the bioavailability of toxic substances [5]. The direct transfer of chemicals from sediments to organisms is now considered to be a major route of exposure for many species. To evaluate the contaminant release from sediment through desorption processes, both the characteristics of the sediment and the overlying water column must be considered [1]. Contaminants may be mobilized by changes in geochemical parameters (e.g. $\mathrm{pH}$ ), by diffusion of pollutants into the water body because of concentration gradients, by oxidation of anoxic sediments through bioturbation or resuspension caused by flooding, as well as by degradation processes leading to a more mobile form [6].

The estimated costs for the cleanup of contaminated sites with conventional techniques, involving incineration or landfilling, are enormous. When dredging or related techniques are applied the environmental problem is not eliminated but only moved to another compartment. The cleanup of all contaminated sites in the United States alone would mount to a sum of approximately US\$1.7 trillion [7]. Therefore, more cost-effective and less invasive technologies are necessary.

This review aims to give an overview over remediation techniques in use, like dredging, capping, and monitored natural recovery (MNR). Also, new alternatives are presented, some of which are already in phase of pilot scale application and promise to cause less environmental impact and at the same time to be more cost efficient.

\section{Organic pollutants}

Hydrocarbons in sediments originate from diverse sources, which can be summarized in the following categories $[8,9]$ :

- anthropogenic (industrial chemicals);

- petroleum inputs;

- incomplete combustion of fuels;

- forest and grass fires;
- biosynthesis of hydrocarbons by aquatic or terrestrial organisms;

- post-depositional transformation of biogenic precursors;

- diffusing from the mantle, petroleum source rocks or reservoirs.

Persistent organic pollutants and emerging contaminants have been described in several reviews (see Eljarrat and Barceló [10] for a priority list of these pollutants based on their relative toxic potential in environmental samples). The following list should serve to give an overview of contaminant groups mentioned later on in the discussion of remediation technologies.

\subsection{Polycyclic aromatic hydrocarbons (PAHs)}

Polycyclic aromatic hydrocarbons (PAHs) are ubiquitous pollutants. There are over 100 different PAH compounds. PAHs are mainly formed by incomplete combustion of organic substances and rarely are of industrial use, except for a few PAHs used in medicines and the production of dyes, plastics and pesticides [11]. They are highly toxic to organisms due to their carcinogenic and mutagenic potential. Because of their low water solubility and hydrophobicity, they tend to adsorb on and accumulate in sediments, where the degradation of PAHs with high molecular weights is particularly slow [12]. Sixteen individual PAH compounds have been classified as priority pollutants by the United States Environmental Protection Agency (US-EPA, Table 1) due to their toxic, mutagenic and carcinogenic characteristics [4] and chronic toxic effects from high PAH concentrations in sediments on benthic and aquatic organisms have been reported [2].

\subsection{Polychlorinated biphenyls (PCBs)}

Polychlorinated biphenyls, PCBs, are among the worst pollutants because of their toxicity, carcinogenicity, wide distribution and slow biodegradation in the environment [13]. Hundreds of thousands of metric tons of commercial PCBs (e.g. Aroclors) persist in aquatic sediments [14]. PCBs are used in hydraulic fluids, plasticizers, adhesives and lubricants, flame retardants and dielectric fluids in transformers. They are released during production, from spillage and disposal [15].

\subsection{Polychlorinated dibenzo-p-dioxins and dibenzofurans (PCDD/Fs)}

Polychlorinated dibenzo-p-dioxins and dibenzofurans (PCDD/Fs) have been deposited decades ago and are still found in deep sediment layers. PCDD/Fs are often considered recalcitrant towards biotic and abiotic degradation processes [16]. Thus, they are among the most notorious environmental pollutants. Some congeners, particularly those with lateral chlorine substitutions at positions 2, 3, 7 and 8, are extremely toxic and carcinogenic to humans [17].

\subsection{Others}

Another group of contaminants found frequently in the environment are chlorinated compounds such as trichloroethene, carbon

Table 1

The 16 PAH priority pollutants defined by US-EPA.

\begin{tabular}{|c|c|c|c|c|}
\hline Two-ring & Three-ring & Four-ring & Five-ring & Six-ring \\
\hline Naphthalene & Fluoranthene & Crysene & Benzo[a]pyrene & Benzo[g,h,i]perylene \\
\hline Fluorene & Phenanthrene & Pyrene & Indeno[ $[1,2,3-c, d]$ pyrene & \\
\hline Acenaphthene & Anthracene & Benzo[a]anthracene & Dibenzo[a,h]anthracene & \\
\hline \multirow[t]{2}{*}{ Acenaphthylene } & & Benzo[b]fluoranthene & & \\
\hline & & Benzo[k]fluoranthene & & \\
\hline
\end{tabular}


tetrachloride, and pentachlorophenol, which are used as solvents and for wood treatment [15].

\section{Remediation strategies}

The first step of any contaminated sediment management strategy, before applying any of the available remediation techniques, is the contaminant source control or elimination. The two main objectives of sediment management strategies are on one hand to minimize contaminant risk to human health and the environment, and on the other hand to minimize cost. A third goal gaining importance is to minimize the risks associated with the remediation technique itself, like habitat destruction and/or modification [18].

Usually one of the following response actions is used in sediment remediation today: dredging, capping or monitored natural recovery (MNR).

\subsection{Dredging and related technologies}

\subsubsection{Dredging}

Dredging consists in the physical removal of the contaminated sediment layers. Typically, it is the most expensive technique (Table 2) which results in the greatest mass removal from the aquatic environment [18]. But at the same time it only shifts the contamination problem to another place, as the removed sediment has to be deposed elsewhere and thus requires further management. The effectiveness of dredging in sediment remediation has been questioned in recent years due to several limitations of this technique. The dredge may miss contaminated areas and residual contaminated sediment may mix with underlying or surrounding sediment. Resuspended material can migrate downstream and affect ecosystems there as well. Dredging may lead to longor short-term increases of contaminant bioavailability, facilitating pollutant entrance into food-chains. As dredging is also the most invasive technique, it very likely leads to the alteration or destruction of the benthic community. Furthermore the presence of boulders and debris may limit the effectiveness and impede the achievement of low contaminant cleanup levels [19].

Nevertheless, dredging has been applied in lakes, rivers and harbors in the USA and other countries because it permanently removes the contaminated sediment. In the US, about six million yards [18] of contaminated sediment have been removed and dis- posed during 71 major remediation projects. Most of the removed material was disposed in landfills, but some disposal has been realized in confined aquatic disposal (CAD) cells, leading to considerable cost savings.

Analysis of pre- and post-dredging by the NRC Committee on Sediment Dredging at about 20 Superfund Megasites [20] found a wide range of outcomes in terms of surface sediment concentration of contaminants; from increase, over no change, to decreases in concentrations. About one half of the 20 sites evaluated by the committee either did not achieve remedial goals or monitoring was insufficient to assess dredging performance. Remedial goals were met at about $25 \%$ of the sites and at another $25 \%$ remediation action was too recent for judgment. The NRC report concludes that dredging alone has not achieved remediation objectives at the majority of sites.

\subsubsection{Dry excavation}

Dry excavation differs from dredging, since the removal of sediment follows a significant dewatering of the water body, which enhances access to the contaminated areas and minimizes contaminant migration downstream during excavation. As with dredging, removed sediment requires subsequent treatment and/or deposition. This technique is very expensive and poses similar benefits and limitations as dredging, in addition to the technical challenge of maintaining "dry" conditions [21].

\subsection{Capping and related technologies}

\subsubsection{Capping}

Capping consists of covering the contaminated sediment surface with clean material, thus isolating the sediments. Potential benefits are the reduction of contaminant water-column concentrations and therefore reduced bioavailability to benthic and aquatic organisms, as well as the minimization of downstream migration. Applying caps to contaminated sediment is typically less expensive than dredging, with costs depending primarily on cap design (Table 2). Capping requires long-term monitoring and poses a certain risk because contaminants are left in place [18]. During the placement of capping material, contaminated sediments can be mixed with the clean material or resuspended. Placement may be challenging in deeper waters, areas with wave action, boat traffic, or large targeted surface areas. Long-term risks are the erosion of the cap and diffusion of contaminants through the cap material, as well as the

Table 2

Cost $[\$]$ per $\mathrm{m}^{3}$ of remediated sediment treated by dredging, capping and bioremediation.

\begin{tabular}{|c|c|c|c|c|c|c|}
\hline Site & Technique & Area $\left[\mathrm{m}^{3}\right]$ & Pollutant & Cost $[\$]$ & Material & Cost $[\$]$ per $\mathrm{m}^{3}$ \\
\hline Thunder Bay a & Dredging & 13,000 & Creosote & $9,300,000$ & & 715.00 \\
\hline St. Louis River ${ }^{a}$ & Dredging & 1892 & Murphy oil & 250,000 & & 132.00 \\
\hline Manistique River a & Dredging & 44,100 & PCB & $25,000,000$ & & 567.00 \\
\hline Kalamazoo River a & Dredging & 3700 & PAH, mercury, lead & 900,000 & & 243.00 \\
\hline Shiawassee River a & Dredging & 35,600 & PCB & $13,558,000$ & & 381.00 \\
\hline River Raisin ${ }^{a}$ & Dredging & 20,000 & PCB & $6,000,000$ & & 300.00 \\
\hline Maumee River ${ }^{a}$ & Dredging & 6100 & PCB & $5,000,000$ & & 820.00 \\
\hline St Clair River ${ }^{a}$ & Dredging & 200 & Pentachlorophenol & 350,000 & & 1750.00 \\
\hline Niagara River a & Dredging & 13,000 & Dioxin & $14,000,000$ & & 1077.00 \\
\hline Minamata Bay, Japan ${ }^{\text {b }}$ & Capping & 582,000 & & $388,000,000$ & $\begin{array}{l}1.5 \text { mio } \mathrm{m}^{3} \text { of clean } \\
\text { sediment }\end{array}$ & 667.00 \\
\hline Little Lake Butte des Morts ${ }^{\text {b }}$ & Capping & 170,000 & & $7,565,000$ & $\begin{array}{l}\text { Two } 30-\mathrm{cm} \text { layers of fill } \\
\text { and cobbles and two } \\
\text { geotextile layers }\end{array}$ & 44.50 \\
\hline New Bedford Harbor ${ }^{b}$ & Capping & 760,000 & & 32.832 .000 & $\begin{array}{l}\text { 1-m layer of sand on top } \\
\text { of a geotextile }\end{array}$ & 43.20 \\
\hline Hamilton Harbor ${ }^{\mathrm{a}, \mathrm{b}}$ & Capping & 10,000 & $\begin{array}{l}\text { Heavy metals, PCB, } \\
\text { PAH }\end{array}$ & 650,000 & $50-\mathrm{cm}$ layer of sand & 65.00 \\
\hline Hamilton Harbor ${ }^{\mathrm{a}, \mathrm{b}}$ & Bioremediation & 414,103 & & 323,000 & $\begin{array}{l}\text { Injection of oxygen, iron } \\
\text { oxide, calcium nitrate }\end{array}$ & 0.78 \\
\hline
\end{tabular}

\footnotetext{
a Ref. [83].
}

b Ref. [84]. 
disruption of groundwater seepage patterns, and the creation of flow bypassing around the caps [22]. Depending on the capping material used, benthic communities may be altered. The presence of an in situ cap shifts the deposition of labile organic matter to the newly formed cap-water interface, thus removing a source of carbon and organic substrates from the biologically active sediment, where biotransformations are most likely to occur [3].

Cap design can be very variable. Sand is the traditional material employed for capping, but also other natural or synthetic materials of varying sizes are available. The design of reactive caps to sequester of transform contaminants has been an objective of investigations recently [23-27].

Jacobs and Foerstner [27] proposes the use of natural zeolites as capping material, as they are easily available and can be transformed into a powerful sorptive agent. Zeolites are mined as a brittle, solid rock, whose grain size distribution can be controlled freely. More coarse grained material settles readily onto the surface sediments, which facilitate its application in subaqueous environments. Zeolites can be transformed to a powerful sorptive agent by pre-treatment of surfaces with cationic surfactants. Such surface activated zeolites facilitate the retention of non-polar contaminants in aquatic systems.

Natural organic material from different plant sources in various forms of cellulose, hemicellulose, lignin, and humics were tested as sorbents after activating them by superheated water processing $[24,25]$. This pre-treatment increased condensation and aromatization of these organic materials, two characteristics that were shown to be directly related to their sorption-desorption properties. These engineered natural organic sorbents were successfully tested for phenanthrene retention, indicating a strong potential for the production of an efficient and cost-effective material for environmental applications.

Murphy et al. [26] evaluated the effectiveness of applying a thin layer $(1.25 \mathrm{~cm})$ of an active sorbent like organic-rich soil, coke or activated carbon between the contaminated sediment and a conventional sand cap of $15 \mathrm{~cm}$. In the absence of groundwater seepage the thin layer of capping material was estimated to provide isolation for more than 500 years and lowered PCB flux into the bioactive zone compared to pure sand caps. Even with moderate groundwater seepage of $1 \mathrm{~cm}$ per day, high capacity sorbents, such as activated carbon, could still provide long isolation times.

\subsubsection{Geotextile mats}

Geotextiles are part of the geosynthetics family. According to the ASTM D 4439 [28] the geotextile is defined as "a permeable geosynthetic comprised solely of textiles. Geotextiles are used with foundation, soil, rock, earth, or any other geotechnical engineering-related material as an integral part of human-made project, structure, or system." Geotextiles are permeable, polymeric structures in the form of flexible sheets most commonly made of polypropylene. Based on their manufacturing process they can be classified into the following categories: (i) woven geotextiles, made from yarns by waving process; (ii) non-woven geotextiles, made from directionally or randomly oriented fibers bonded together; (iii) knitted geotextiles, made from interloping yarns; and (iv) stitch-bonded geotextiles, made of fibers or yarns stitched together [29]. The four most common applications of geotextiles are in filtration, separation, reinforcement and drainage processes.

Geotextile mats are also used in sediment capping processes. They can be used as an underlay stabilizing the actual cap material (as realized at Little Lake Butte des Morts, Table 2) or include reactive sorptive agents encapsulated into carrier textiles, which are adhered together to provide product integrity. The Contaminated Sediments Center of the University of New Hampshire is currently evaluating the efficiency of such reactive core mats, which include a combination of sorbants capable of sequestering both heavy met- als and organic contaminants (www.unh.edu). Applying geotextile mats as sediment caps allows to place a thin layer of reactive media in a stable and precise manner [30]. On the other hand the use of mats increases the isolation of the sediment from organic matter and benthic organisms more than capping with granulate material.

\subsubsection{Sediment mixing with sorptive agents}

Instead of including reactive sorbants in the capping material, they can be mixed with the sediment to immobilize contaminants in place and thus reduce their bioavailability and access to the food-chain. Zimmerman et al. [23] compared the sorptive activity of coke and activated carbon mixed with the biologically active layer of contaminated sediment at Hunters Point Naval Shipyard, CA. Activated carbon was the more effective sorbent, due to its much greater specific surface area and a pore structure favorable for binding contaminants. Treatment with activated carbon was capable of reducing aqueous equilibrium $\mathrm{PCB}$ and $\mathrm{PAH}$ concentration by 92\% and 84\%. Related studies also show that the treatment significantly reduced the bioavailability of PCBs to filter feeding and soil dwelling organisms in laboratory experiments [31] as well as field pilot scale studies [32]. Amendment of sediments with activated carbon reduced the bioavailability of DDT to mussels in laboratory tests [33] as well.

\section{Bioremediation technologies}

The term "bioremediation" describes the process of contaminant degradation in the environment by biological methods using the metabolic potential of microorganisms to degrade a wide variety of organic compounds [15].

The main advantage of bioremediation is its reduced cost compared to conventional techniques (Table 2). Therefore they are of major interest since the cost of remediation with conventional techniques of all contaminated sites in the USA alone is estimated to be $\$ 1.7$ trillion [34].

Besides cost-effectiveness, it is a permanent solution, which may lead to complete mineralization of the pollutant. Furthermore, it is a non-invasive technique, leaving the ecosystem intact. Bioremediation can deal with lower concentration of contaminants where the cleanup by physical or chemical methods would not be feasible. Unfortunately, it presents some major drawbacks, which still limit the application of these techniques, including the fact that processes may take longer and are less predictable than conventional methods.

The strategies for bioremediation can be the following:

- Monitored natural recovery (MNR): using the "self-healing" natural capacities of the indigenous microbial population in combination with natural occurring physical and chemical processes.

- Biostimulation: encouraging the indigenous population by influencing the factors which affect microbial growth.

- Bioaugmentation: introducing appropriate species for the degradation of specific contaminants.

- Phytoremediation: using plants and algae in the degradation and removal of contaminants from the environment.

Bioremediation strategies may be applied in combination, e.g. phytoremediation and biostimulation. Here, the use of plants can also enhance the activity of degrading microorganisms in their root system, then called "rhizoremediation".

\subsection{Monitored natural recovery (MNR)}

Monitored natural recovery is the only bioremediation strategy applied in sediment management currently. This technique 
involves leaving contaminated sediments in place and allowing ongoing natural processes like aquatic sedimentation and biological and chemical transformation to degrade or immobilize the contaminant in situ, thus reducing its bioavailability [35].

Although no action is required to initiate or continue the process, natural recovery is considered the result of a deliberate, thoughtful decision following detailed site assessment and characterization [19].

Magar [35] identified several physical, chemical and biological processes, which contribute to MNR. The burial of contaminants by the natural deposition of clean sediments reduces surface sediment concentrations over time. Sorption to active compounds present in the sediment reduces contaminant mobility and bioavailability. Particle-bound contaminants may leave the site of contamination by erosion, transport and dispersion, which removes them from the contaminated site but may increase contaminant concentrations in downstream areas. Contaminants can be converted to less toxic forms or degraded to its molecular constituents.

Compared to dredging and capping, MNR is the least expensive response action, but requires extensive long-term monitoring. MNR is considered most effective for low-risk sites with low level or diffuse contamination, where human health and ecological risks are not immediate or substantial $[18,36]$.

Before choosing MNR as remediation strategy, Magar and Wenning [36] suggest several lines of evidence that should be considered in sediment investigation prior to decision making:

1. Documentation (and possibly confirmation of source control).

2. Evidence of contaminant burial and reduction of surface sediment concentrations.

3. Measurement of surface sediment mixing to estimate the active sediment benthic layer and to determine the surface sediment depth to which remedial action objectives should be applied.

4. Measurement of sediment stability to assess the risk of contaminant resuspension under normal and high-energy events.
5. Evidence of contaminant transformation and risk attenuation.

6. Modeling of long-term recovery, including surface water, sediment, and biota.

7. Monitoring ecological recovery and long-term risk reduction.

8. Knowledge of future site use and institutional controls.

MNR is considered the most appropriate strategy where it can be assured that contaminants will be buried or transformed in an acceptable time and where the ecological impacts of dredging and capping would have greater negative impacts [36].

\subsection{Biostimulation}

The biological degradation of contaminants in sediment is usually realized by anaerobic metabolism, due to the mostly anaerobic sediment conditions. As anaerobic metabolic pathways need electron acceptors other than oxygen, stimulation of these pathways is achieved by adding these acceptors.

Studies on benzene degradation in sediments from a petroleumcontaminated aquifer showed anaerobic benzene degradation when electron acceptors like Fe (III), sulfate, nitrate and humic substances were available [37].

Major et al. [38] conducted a pilot scale field test to evaluate the dechlorination of tetrachloroethene (PCE) to ethene, a degradation pathway which produces trichloroethene (TCE) and cis-1,2-dichloroethene ( $C D C E$ ) as intermediates. The first stage of the remediation test consisted in stimulating the indigenous microbial population by injecting methanol and acetate as electron donors. Under these conditions dechlorination of PCE was enhanced but stopped at CDCE and was not completed, due to the lack of specialized microorganisms capable of the last reduction step. A summary of biostimulation and bioaugmentation outcomes for remediation by reductive dechlorination is given in Table 3.

Table 3

Reductive dechlorination of different pollutants by natural attenuation, biostimulation and bioaugmentation.

\begin{tabular}{|c|c|c|c|c|c|c|}
\hline Pollutant & Conc. & Duration & Reduction & Resulting compound & Species and conditions & Reference \\
\hline $1,2,3,4-\mathrm{TeCDD}^{\mathrm{a}}$ & $50 \mu \mathrm{M}$ & $388 d$ & $37 \mathrm{~mol} \%$ & $1,3-\mathrm{DCDD}^{\mathrm{b}}$ & Intrinsic community & [85] \\
\hline PCB mixture Aroclor 1260 & $50 \mu \mathrm{g} / \mathrm{ml}$ & $160 \mathrm{~d}$ & $64.2 \%$ & & Dehalococcoides & {$[64]$} \\
\hline $1,2,3-\operatorname{TrCDD}^{\mathrm{c}}$ & $25 \mu \mathrm{M}$ & $57 \mathrm{~d}$ & $60 \mathrm{~mol} \%$ & 2-MCDD d & Dehalococcoides strain CBDB1 & [65] \\
\hline $1,2,4-\operatorname{TrCDD}$ & $60 \mu \mathrm{M}$ & $57 d$ & $37 \mathrm{~mol} \%$ & 1,3-DCDD, 2-MCDD & & \\
\hline $1,2,3,4-\mathrm{TeCDD}$ & $46 \mu \mathrm{M}$ & $84 \mathrm{~d}$ & $24 \mathrm{~mol} \%$ & 2,3-DCDD, 2-MCDD & & \\
\hline \multirow[t]{5}{*}{$\mathrm{PCE}^{\mathrm{e}}$} & $80 \mu \mathrm{M}$ & $82 \mathrm{~d}$ & $100 \%$ & Ethene & Intrinsic community & \multirow[t]{5}{*}{ [3] } \\
\hline & $80 \mu \mathrm{M}$ & $80 \mathrm{~d}$ & $100 \%$ & Ethene & Intrinsic community $+\mathrm{H}_{2}$ (low) & \\
\hline & $80 \mu \mathrm{M}$ & $76 \mathrm{~d}$ & $100 \%$ & Ethene & Intrinsic community + acetate $+\mathrm{H}_{2}$ & \\
\hline & $80 \mu \mathrm{M}$ & $56 d$ & $100 \%$ & Ethene & Intrinsic community $+\mathrm{H}_{2}$ (high) & \\
\hline & $80 \mu \mathrm{M}$ & $33 \mathrm{~d}$ & $100 \%$ & Ethene & PCE to ethene mixed culture & \\
\hline \multirow[t]{2}{*}{ PCE } & \multirow[t]{2}{*}{$\sim 10 \mu \mathrm{M}$} & $121 \mathrm{~d}$ & $76 \%$ & Ethene & Intrinsic community + lactate + nutrients & \multirow[t]{2}{*}{ [66] } \\
\hline & & $43 d$ & $92 \%$ & Ethene & Dehalococcoides containing inoculum & \\
\hline \multirow[t]{8}{*}{ PCE } & \multicolumn{3}{|c|}{ Microcosm study } & & & \multirow[t]{8}{*}{ [38] } \\
\hline & $6 \mu \mathrm{M}$ & $17 \mathrm{~d}$ & $100 \%$ & $\mathrm{CDCE}^{\mathrm{g}}$ & Intrinsic community + lactate & \\
\hline & $6 \mu \mathrm{M}$ & $23 \mathrm{~d}$ & $100 \%$ & $\mathrm{cDCE}$ & Intrinsic community + methanol & \\
\hline & $6 \mu \mathrm{M}$ & $57 \mathrm{~d}$ & $100 \%$ & Ethene & Dehalococcoides KB1 & \\
\hline & $600 \mu \mathrm{M}$ & $150 \mathrm{~d}$ & $100 \%$ & Ethene & Dehalococcoides KB1 & \\
\hline & Pilot plot & & & & & \\
\hline & & $173 d$ & $90 \%$ & $\mathrm{cDCE}$ & Intrinsic community + methanol + acetate & \\
\hline & & $142 \mathrm{~d}$ & Predominant & Ethene & Dehalococcoides KB1 & \\
\hline \multirow[t]{2}{*}{ TCE $^{f}$} & $4800 \mu \mathrm{g} / \mathrm{L}$ & $269 d$ & & $\mathrm{cDCE}$ & Intrinsic community & \multirow[t]{2}{*}{ [86] } \\
\hline & $4800 \mu \mathrm{g} / \mathrm{L}$ & $150 \mathrm{~d}$ & $100 \%$ & Ethene & Dehalococcoides containing inoculum & \\
\hline
\end{tabular}

a Tetrachlorodibenzo-p-dioxin.

b Dichlorodibenzo-p-dioxin.

c Trichlorodibenzo-p-dioxin.

d Monochlorodibenzo-p-dioxin.

e Tetrachloroethene.

f Trichloroethene.

g Dichloroethene. 


\subsubsection{Surfactants}

A general problem in biodegradation is the availability of the contaminant to the degrading organisms. Bioavailability of a pollutant depends largely on its physical and chemical properties: the more complex the structure and the less soluble the substance, the more recalcitrant it turns for biodegradation. Surfactants are used as potential agents for enhanced solubility and removal of contaminants from soil and sediments [39-42]. Both biosurfactants, like bile salt, sodium taurocholate, and synthetic surfactants, like Triton X-100 and sodium dodecyl sulphate, have proved to increase the bioavailability of contaminants like PAHs and PCBs [43-45].

The use of surfactants, of biological and synthetic origin, has been investigated in several studies and the results vary between facilitating, retarding or not affecting the biodegradation at all [46]. Several factors may reduce the effectiveness of surfactants in remediation processes. An important parameter is the adsorption of the surfactant to soil or sediment, since the amount of surfactants adsorbed decreases the concentration available for dissolving the contaminant $[47,48]$. The degradation of hydrocarbons is affected by biosurfactants because they increase the solubility of the contaminant in the aqueous phase and change the affinity between the microbial cells and the hydrocarbons by increasing cell surface hydrophobicity [49]. But this does not always lead to increased biodegradation, for instance when surfactants inhibit the degradation by detaching the cells from the contaminant-water interface [50,51], when the surfactant itself turns to be substrate to degrading microorganisms [52-54] or when the surfactant causes a toxic effect on the biodegrading microorganisms $[55,56]$.

\subsection{Bioaugmentation}

Bioaugmentation is the introduction of microorganisms with specific catabolic abilities into the contaminated environment in order to supplement the indigenous population and to speed up or enable the degradation of pollutants.

The efficacy of bioaugmentation is a subject of discussion where both, positive and negative results have been reported. Bioaugmentation has proven successful for remediation of PAHs in sediments with poor or lacking intrinsic degradation potential $[38,57]$ while other studies demonstrated that bioaugmentation did not enhance biodegradation significantly compared to natural attenuation [58].

One of the main problems in applying bioaugmentation is to ensure the survival and activity of the introduced organisms in the environment. Bioaugmentation can be inhibited by a variety of factors including $\mathrm{pH}$ and redox, the presence of toxic contaminants, concentration and bioavailability of contaminants, or the absence of key co-substrates. But the key factor to successful bioaugmentation is the selection of the appropriate bacterial strain for this purpose. When selecting the strain for augmentation purposes, the kind of microbial communities present in the source habitat should be considered [59].

Selecting a strain for remediation purposes, by not only accounting for degradation abilities but also for ecological characteristics concerning adaptation to the habitat, has already shown success. In a series of experiments aiming to develop a bacterial inocula to treat spent metal working fluids in bioreactors three criteria where used to select strains: (i) the relative abundance of the source populations in the target habitat (waste), (ii) tolerance to co-contaminants and (iii) the ability to degrade target contaminants [60]. The final consortium of four strains was $85 \%$ more effective at processing the waste than undefined inocula from sewage. Its performance was also more consistent and predictable [61].
In another approach Diaz et al. [62] isolated a petroleum degrading consortium which was able to tolerate high salinity ranges. High salinity ranges are a common restriction in applying bioaugmentation to marine sediments, like mangroves. The consortium isolated from the roots of oil polluted mangroves showed both, degradation abilities and a high resistance to salinity variations, degrading crude oil in the absence of salt and at salt concentrations as great as $220 \mathrm{~g} \mathrm{~L}^{-1}$.

Bioaugmentation strategies may prove successful especially in the remediation of man-made contaminants, where specialized bacteria with the appropriate catabolic pathways may not be present in the contaminated habitat.

Halogenated organic compounds, like PCBs, PCDD/Fs and chlorinated ethenes, generally are recalcitrant and accumulate in sediments. Many of these substances are toxic and carcinogenic. The toxicity and persistence of halogenated organic compounds depends on the number of halogen molecules, their position and the type of halogen [15].

Microbial reductive dechlorination or dehalorespiration is a promising mechanism for the detoxification and degradation of these halogenated compounds. In anoxic, reductive environments like sediments, specific dehalorespiring microorganisms utilize chlorinated compounds as their terminal electron acceptors and gain energy from reductive dechlorination, substituting a halogen by a hydrogen atom. Of these dehalorespiring organisms, Dehalococcoides strains have been identified to be relevant for the degradation of chlorinated ethenes [63], commercial PCB mixtures (e.g. Aroclors) [64] and polychlorinated dibenzo-p-dioxins and dibenzofurans (PCDD/Fs) [65].

Assessing the fate of PCDD/Fs after sedimentation in an urban (Tokyo Bay) and remote location (Lake Shinji) in Japan, Uchimiya and Masunaga [16] estimated natural dechlorination times for the formation of $1,2,3,4,6,7,9-\mathrm{HpCDD}$ to be at least $27.8+17.9$ years $(\mathrm{mol} \%)^{-1}$ in Lake Shinji and $4.7+0.5$ years $(\mathrm{mol} \%)^{-1}$ in Tokyo Bay, which are significantly longer than the dechlorination pathways observed in the laboratory.

In a series of laboratory and field experiments Major et al. [38] and Lendvay et al. [66] measured the effects of natural attenuation, biostimulation and bioaugmentation of a contaminated aquifer with a Dehalococcoides containing inoculum to evaluate the dechlorination of PCE to intermediates ( $\mathrm{CDCE}$ ) or completely to ethene, as well as to monitor the presence of dehalorespiring bacteria with molecular techniques. Biostimulation consisted of establishing reductive conditions by adding methanol and acetate. As the site itself did not contain Dehalococcoides strains capable of dehalogenating PCE completely to ethene, biostimulation only lead to the accumulation of CDCE. The addition of a natural dechlorinating microbial consortium that contained phylogenetic relatives of Dehalococcoides ethenogenes, capable of the last dechlorination step, resulted in the successful dechlorination to ethene (Table 3).

Choosing bioaugmentation as remediation strategy is viable if the limiting factor of biodegradation is the absence of relevant catabolic genes within the indigenous microbial community and this lack of genetic information will be filled by the introduced strain [59].

Genetic information containing degradation abilities may also be introduced by donor species, which themselves do not survive a long time in the environment but pass on the lacking genetic information to intrinsic microorganisms $[67,68]$. Dejonghe et al. [69] introduced the plasmid pEMT1 containing information for the degradation of 2.4-dichlorophoxyacetic acid (2.4-D) by a donor strain to the indigenous soil microbial community. This resulted in complete degradation of $2.4-\mathrm{D}$ after $19 \mathrm{~d}$, while the contaminant persisted in the inoculated soil after $89 \mathrm{~d}$. Degradation was attributed to the emergence of transconjugants, as the donor was undetectable before degradation started. 
Table 4

Comparison of phytoremediation outcomes.

\begin{tabular}{|c|c|c|c|c|}
\hline Pollutant & Conc. & Plant species & Pollutant reduction & Reference \\
\hline \multirow[t]{2}{*}{ Phenanthrene } & $14 \mu \mathrm{g} / \mathrm{g}$ & Salix (willow) & $4.8 \%$ & [87] \\
\hline & & Scirpus (deergrass) & $4.0 \%$ & \\
\hline \multirow[t]{2}{*}{ Chlorobenzene } & $10 \mu \mathrm{g} / \mathrm{g}$ & Salix (willow) & $3.8 \%$ & \\
\hline & & Scirpus (deergrass) & $5.7 \%$ & \\
\hline \multirow[t]{3}{*}{ Petrol hydrocarbons, PAH } & & Alnus (alder) & No effect & {$[80]$} \\
\hline & & Populus (poplar) & & \\
\hline & & Salix (willow) & & \\
\hline Petrol hydrocarbons & & Salix (willow) & $57 \%$ & [79] \\
\hline Carbon tetrachloride, hexachloroethane & & $\begin{array}{l}\text { Spirogyra and Nitella (stonewort), } \\
\text { Myriophyllum aquaticum (parrot } \\
\text { feather), Elodea canidensis } \\
\text { (waterweed) }\end{array}$ & $>80 \%$ & [73] \\
\hline \multirow[t]{2}{*}{ Total PAHs, } & $30 \mu \mathrm{g} / \mathrm{g}$ & Hibiscus tiliaceus (dwarf hau) & $58 \%$ & [78] \\
\hline & & Vetiver zizanoides (vetiver) & $37 \%$ & \\
\hline \multirow[t]{2}{*}{ Benzo[a]pyrene } & $5.6 \mu \mathrm{g} / \mathrm{g}$ & Hibiscus tiliaceus (dwarf hau) & $73 \%$ & \\
\hline & & Vetiver zizanoides (vetiver) & $54 \%$ & \\
\hline \multirow[t]{2}{*}{ PCBs found in Aroclor 1260} & & Carex & $6.8-21 \%$ & [81] \\
\hline & & No plant & $4.2-15.5 \%$ & \\
\hline
\end{tabular}

\subsection{Phytoremediation}

Phytoremediation in terrestrial environments is often applied to remediate heavy metal pollution using hyperaccumulative species to extract the contaminant. Phytoremediation of organic pollutants does not work using hyperaccumulation but has the potential to completely mineralize or transform the pollutant into a less- or non-toxic component. Targets of phytoremediation include PCBs, PAHs, nitroaromatics, and linear halogenated hydrocarbons. The mechanisms of phytoremediation include biophysical and biochemical processes like adsorption, transport and translocation, as well as transformation and mineralization by plant enzymes [13]. Plants have been shown to be able to degrade halogenated compounds like TCE by oxidative degradation pathways, including plant specific dehalogenases [70-73]. Dehalogenase activity was observed to be maintained after the plants death. Enzymes can become bound to the organic matrix of the sediment as plants die, they decay and they are buried in the sediment, thus contributing to the dehalogenase activity observed in organic-rich sediments [73].

In the rhizosphere plant roots interact with the present microorganisms and may enhance their degradation activities by supplying them with nutrients from root exudates [72,74-76].

Major drawbacks of phytoremediation include the fact that the detoxification of organic pollutants is often slow and if decomposition is not complete, toxic compounds may accumulate in plant tissue and can be released to the environment or enter food-chains [77].

The application of phytoremediation for sediments has been investigated mostly for the remediation of dredged sediments disposed in landfills but also for in situ remediation of shallow waters.

Dredged contaminated sediment generally is disposed in confined landfills. Studies about the remediation of these sediments by plants resulted in diverse outcomes, ranging from near $90 \%$ reduction [78], to little remediation enhancement $[79,80]$ or even negative effects [81], depending on the contaminant, the environment and the plant species used for decontamination. In the case of negative effects, plant roots contributed to the aeration of the sediment, interfering with the highly reducing conditions needed for reductive dechlorination. Table 4 gives an overview of different phytoremediation outcomes.

Not only vascular plants but also algae may be used for remediation purposes. In a recent study [82] benthic microalgae (BMA) have been used for the first time in the remediation of organically enriched sediments. Intrinsic BMA species were mass cultured in the laboratory and reintroduced to the environment attached to glass beads. Re-plantation of BMA changed the reduced conditions of the organic-rich sediment to toxic, thus enhancing the degradation of the organic material.

\section{Conclusions}

All remediation techniques present specific advantages and disadvantages, which have to be evaluated according to each situation. The main disadvantages of the two conventional management strategies, dredging and capping, are their considerable impact on the environment and the need for high investment. Bioremediation approaches promise to eliminate these factors, but their major drawback, as they are biological systems, is their low predictability and sometimes long degradation times, which involve extensive monitoring activities. Also, many biodegradation experiments are done in laboratory experiments and work differently under the diversity of factors influencing these systems under field conditions.

For future improvement, more field data and pilot plot scale experiments are essential in order to make bioremediation a reliable option of remediation activities. The application of molecular techniques may help to identify potential remediating organisms and to discover what makes some species more persistent than others. Improving the knowledge about microbial diversity in natural environments may lead to the development of a culture collection of well-characterized organisms with degradation abilities and high tolerance to a broad range of environmental chemical and physical stresses [59] in the future. This ultimately may lead to a increasingly robust and reliable bioremediation, capable of replacing more invasive techniques.

\section{References}

[1] T. Zoumis, A. Schmidt, L. Grigorova, W. Calmano, Contaminants in sediments: remobilization and demobilization, Sci. Total Environ. 266 (2001) 195-202.

[2] F. Martínez-Jerónimo, J.L. Cruz-Cisneros, L. García-Hernández, A comparison of the response of Simocephalus mixtus (Cladocera) and Daphnia magna to contaminated freshwater sediments, Ecotoxicol. Environ. Saf. 71 (2008) 26-31.

[3] D.W. Himmelheber, K.D. Pennell, J.B. Hughes, Natural attenuation processes during in situ capping, Environ. Sci. Technol. 41 (2007) 5306-5313.

[4] IARC (International Agency for Research on Cancer), in: IARC (Ed.), IARC Monographs on the Evaluation of the Carcinogenic Risk of Chemicals to Humans: Polynuclear Aromatic Compounds Part I, IARC Press, Lyon, 1983.

[5] L. Viganó, Assessment of the toxicity of river Po sediments with Ceriodaphnia dubia, Aquat. Toxicol. 47 (2000) 191-202.

[6] K. Booij, E.P. Achterberg, B. Sundby, Release rates of chlorinated hydrocarbons from contaminated sediments, Neth. J. Sea Res. 29 (1992) 297-310.

[7] I. Kuiper, E.L. Lagendijk, G.V. Bloemberg, B.J.J. Lugtenberg, Rhizoremediation: a beneficial plant-microbe interaction, Mol. Plant Microbe Interact. 17 (2004) 6-15. 
[8] J.W. Readman, G. Gillmann, I. Tolosa, J. Bartocci, J. Villeneuve, C. Catinni, L.D. Mee, Petroleum and PAH contamination of the Black Sea, Mar. Pollut. Bull. 44 (2002) 48-62.

[9] G.B. Kim, K.A. Maruya, R.F. Lee, J.H. Lee, C.H. Koh, S. Tanabe, Distribution and sources of polycyclic aromatic hydrocarbons in sediments from Kyeonggi Bay, Korea, Mar. Pollut. Bull. 38 (1999) 7-15.

[10] E. Eljarrat, D. Barceló, Priority lists for persistent organic pollutants and emerging contaminants based on their relative toxic potency in environmental samples, Trend Anal. Chem. 22 (2003) 655-665.

[11] US-EPA Great Lakes National Program Office, Realizing Remediation: A Summary of Contaminated Sediment Remediation Activities in the Great Lakes Basin, 1998.

[12] J.W. Readman, R.F.C. Mantoura, M.M. Rhead, L. Brown, Aquatic distribution and heterotrophic degradation of polycyclic aromatic hydrocarbons (PAH) in the Tamar estuary, Estuar. Coas. Shelf Sci. 14 (1982) 369-389.

[13] R.B. Meagher, Phytoremediation of toxic elemental and organic pollutants, Curr. Opin. Plant Biol. 3 (2000) 153-162.

[14] NRC National Research Council, Polychlorinated Biphenyls, 1979.

[15] A. Scragg, Bioremediation, Environ. Biotechnol. (2005) 173-229.

[16] M. Uchimiya, S. Masunaga, Time trend in sources and dechlorination pathways of dioxins in agrochemically contaminated sediments, Environ. Sci. Technol. 41 (2007) 2703-2710.

[17] J. Kaiser, Just how bad is dioxin? Science 288 (2000) 1941-1944.

[18] C. Zeller, B. Cushing, Panel discussion: remedy effectiveness: what works, what doesn't, Integr. Environ. Assess. Manage. 2 (2005) 75-79.

[19] NRC National Research Council, Contaminated Sediments in Ports and Waterways, 1997.

[20] National Research Council, Sediment Dredging at Superfund Megasites: Assessing the Effectiveness, 2007

[21] S.C. Nadeau, Understanding Remediation at Contaminated Sediment Sites: Advantages, Limitations, and Risks Associated with Sediment Management, 2008.

[22] D.D. Reible, D. Lambert, D.W. Constant, R.D. Mutch, Y. Zhu, Active capping demonstration in the Anacostia River, Washington, DC, Remediation 17 (2006) 39-53.

[23] J.R. Zimmerman, U. Ghosh, R.N. Millward, T.S. Bridges, R.G. Luthy, Addition of carbon sorbents to reduce PCB and PAH bioavailability in marine sediments: physicochemical tests, Environ. Sci. Technol. 38 (2004) 5458-5464.

[24] J. Tang, W.J. Weber, Development of engineered natural organic sorbents for environmental applications. 2. Sorption characteristics and capacities with respect to phenanthrene, Environ. Sci. Technol. 40 (2006) 1657-1663.

[25] W.J. Weber, J. Tang, Q. Huang, Development of engineered natural organic sorbents for environmental applications. 1. Materials, approaches, and characterizations, Environ. Sci. Technol. 40 (2006) 1650-1656.

[26] P. Murphy, A. Marquette, D. Reible, G.V. Lowry, Predicting the performance of activated carbon-, coke- and soil-amended thin layer sediment caps, ASCE 132 (2006) 787-794.

[27] P.H. Jacobs, U. Foerstner, Concept of subaqueous capping of contaminated sediments with active barrier systems (ABS) using natural and modified zeolites, Water Res. 33 (1999) 2083-2087.

[28] ASTMD 4439, ASTM - American Society for Testing Materials, Standard Terminology for Geosynthetics, 2004.

[29] S. Shukla, M. Lopes, B. Das, E. Palmeira, P. Bourdeau, A. Ashmawy, S. Perkins, R. Berg, B. Christopher, S. Tan, in: S. Shukla (Ed.), Geosynthetics and their Applications, Thomas Telford Publishing, London, 2002.

[30] CETCO Remediation Technologies, Site and Sediment Remediation Products and Technologies, 2007.

[31] P.B. McLeod, S.N. Luoma, R.G. Luthy, Biodynamic modeling of PCB uptake by Macoma balthica and Corbicula fluminea from sediment amended with activated carbon, Environ. Sci. Technol. 42 (2008) 484-490.

[32] Y. Cho, D.W. Smithenry, U. Ghosh, A.J. Kennedy, R.N. Millward, T.S. Bridges, R.G. Luthy, Field methods for amending marine sediment with activated carbon and assessing treatment effectiveness, Mar. Environ. Res. 64 (2007) 541-555.

[33] J.E. Thomaszewski, P.B. McLeod, R.G. Luthy, Measuring and modeling reduction of DDT availability to the water column and mussels following activated carbon amendment of contaminated sediment, Water Res. 42 (2008) 4348-4356.

[34] B. Dixon, Bioremediation is here to stay, ASM News 62 (1996) 527-528.

[35] V.S. Magar, Natural recovery of contaminated sediments, J. Environ. Eng. 127 (2001) 473-474.

[36] V.S. Magar, R.J. Wenning, The role of monitored natural recovery in sediment remediation, Integr. Environ. Assess. Manage. 2 (2006) 66-74.

[37] D.R. Lovley, Anaerobic benzene degradation, Biodegradation 11 (2000) 107-116.

[38] D.W. Major, M.L. McMaster, E.E. Cox, E.A. Edwards, S.M. Dworatzek, E.R. Hendrickson, M.G. Starr, J.A. Payne, L.W. Buonamici, Field demonstration of successful bioaugmentation to achieve dechlorination of tetrachloroethene to ethene, Environ. Sci. Technol. 36 (2002) 5106-5116.

[39] S.W. Jeong, Evaluation of the use of capillary numbers for quantifying the removal of DNAPL trapped in a porous medium by surfactant and surfactant foam floods, J. Colloid Interface Sci. 282 (2005) 182-187.

[40] D.N. Johnson, J.A. Pedit, C.T. Miller, Efficient near-complete removal of DNAPL from three-dimensional, heterogeneous porous media using a novel combination of treatment technologies, Environ. Sci. Technol. 38 (2004) 5149-5156.

[41] C.C. West, J.H. Harwell, Surfactants and subsurface remediation, Environ. Sci. Technol. 26 (1992) 2324-2330.
[42] J.D. Rouse, D.A. Sabatini, R.E. Brown, J.H. Harwell, Evaluation of ethoxylated alkylsulfate surfactants for use in subsurface remediation, Water Environ. Res. 68 (1996) 162-168.

[43] F. Nakajima, A. Baun, A. Ledin, P.S. Mikkelsen, A novel method for evaluating bioavailability of polycyclic aromatic hydrocarbons in sediments of an urban stream, Water Sci. Technol. 51 (2005) 275-281.

[44] I.M. Voparil, L.M. Mayer, Commercially available chemicals that mimic a deposit feeder's (Arenicola marina) digestive solubilization of lipids, Environ. Sci. Technol. 38 (2004) 4334-4339.

[45] M.J. Ahrens, J. Hertz, E.M. Lamoureux, G.R. Lopez, A.E. McElroy, B.J. Brownawell, The role of digestive surfactants in determining bioavailability of sedimentbound hydrophobic organic contaminants to 2 deposit-feeding polychaetes, Mar. Ecol. Prog. Ser. 212 (2001) 145-157.

[46] C.K. Liu, C.W. Li, C.Y. Lin, Micellar-enhanced ultrafiltration process (MEUF) for removing copper from synthetic wastewater containing ligands, Chemosphere 57 (2004) 629-634.

[47] Z. Zheng, J.P. Obbard, Evaluation of an elevated non-ionic surfactant critical micelle concentration in a soil/aqueous system, Water Res. 36 (2002) 2667-2672.

[48] J.F. Lee, P.M. Liao, C.C. Kuo, H.T. Yang, C.T. Chiou, Influence of a nonionic surfactant (Triton X-100) on contaminant distribution between water and several soil solids, J. Colloid Interface Sci. 229 (2000) 445-452.

[49] Y. Zhang, R.M. Miller, Effect of rhamnolipid (biosurfactant) structure on solubilization and biodegradation of n-alkanes, Environ. Microbiol. 61 (1995) 2247-2251.

[50] J.W.C. Wong, M. Fang, Z. Zhao, B. Xing, Effect of surfactants on solubilization and degradation of phenanthrene under thermophilic conditions, J. Environ. Qual. 33 (2004) 2015-2025.

[51] F. Volkering, A.M. Breure, W.H. Rulkens, Microbiological aspects of surfactant use for biological soil remediation, Biodegradation 8 (1998) 401-417.

[52] H. Yu, L. Zhu, W. Zhou, Enhanced desorption and biodegradation of phenanthrene in soil-water systems with the presence of anionic-nonionic mixed surfactants, J. Hazard. Mater. 142 (2007) 354-361.

[53] A. Tiehm, M. Stieber, P. Werner, F.H. Frimmel, Surfactant-enhanced mobilization and biodegradation of polycyclic aromatic hydrocarbons in manufactured gas plant soil, Environ. Sci. Technol. 31 (1997) 2570-2576.

[54] A. Tiehm, Degradation of polycyclic aromatic hydrocarbons in the presence of synthetic surfactants, Appl. Environ. Microbiol. 60 (1994) 258-263.

[55] B.N. Aronstein, Y.M. Calvillo, M. Alexander, Effect of surfactants at low concentrations on the desorption and biodegradation of sorbed aromatic compounds in soil, Environ. Sci. Technol. 25 (1991) 1728-1731.

[56] P.A. Willumsen, U. Karlson, P.H. Pritchard, Response of fluoranthene-degrading bacteria to surfactants, Appl. Microbiol. Biotechnol. 50 (1998) 475-483.

[57] A.L. Juhasz, R. Naidu, Bioremediation of high molecular weight polycyclic aromatic hydrocarbons: a review of the microbial degradation of benzo[a]pyrene Int. Biodeterior. Biodegr. 45 (2000) 57-88.

[58] N.F.Y.Tam, Y.S. Wong, Effectiveness of bacterial inoculum and mangrove plants on remediation of sediment contaminated with polycyclic aromatic hydrocarbons, Mar. Pollut. Bull. 57 (2008) 716-726.

[59] I.P. Thompson, C.J. van der Gast, L. Ciric, A.C. Singer, Bioaugmentation for bioremediation: the challenge of strain selection, Environ. Microbiol. 7 (2005) 909-915.

[60] C.J. van der Gast, A.S. Whiteley, M. Strakey, C.J. Knowles, I.P. Thompson, Bioaugmentation strategies for remediating mixed chemical effluents, Biotechnol. Prog. 19 (2003) 1156-1161.

[61] C.J. van der Gast, A.S. Whiteley, I.P. Thompson, Temporal dynamics and degradation activity of an bacterial inoculum for treating waste metal fluid, Environ. Microbiol. 6 (2004) 254-263.

[62] M.P. Diaz, S.J.W. Gringson, C. Peppiatt, J.G. Burgess, Isolation and characterization of novel hydrocarbon degrading euryhaline consortia from crude oil and mangrove sediments, Mar. Biotechnol. 2 (2000) 522-532.

[63] F.E. Loeffler, E.A. Edwards, Harnessing microbial activities for environmenta cleanup, Curr. Opin. Biotechnol. 17 (2006) 274-284

[64] D.L. Bedard, K.M. Ritalahti, F.E. Loeffler, Dehalococcoides population in sediment-free mixed cultures metabolically dechlorinates the commercial polychlorinated biphenyl mixture Aroclor 1260, Appl. Environ. Microbiol. 73 (2007) 2513-2521.

[65] M. Bunge, A. Lorenz, A. Kraus, M. Opel, W.G. Lorenz, J.R. Andreesen, H. Görisch U. Lechner, Reductive dehalogenation of chlorinated dioxins by an anaerobic bacterium, Nature 421 (2003) 357-360.

[66] J.M. Lendvay, F.E. Löffler, M. Dollhopf, M.R. Aiello, G. Daniels, B.Z. Fathepure, M. Gebhard, R. Heine, R. Helton, J. Shi, R. Krajmalnik-Brown, C.L.J. Major, M.J Barcelona, E. Petrovskis, R. Hickey, J.M. Riedje, P. Adriaens, Bioreactive barriers: a comparison of bioaugmentation and biostimulation for chlorinated solvent remediation, Environ. Sci. Technol. 37 (2003) 1422-1431.

[67] R.R. Fulthorpe, R.C. Wyndham, Transfer and expression of the catabolic plasmid pbrc60 in wild bacterial recipients in a fresh-water ecosystem, Appl. Environ. Microbiol. 57 (1991) 1546-1553.

[68] A. Brokamp, F.R.J. Schmidt, Survival of Alcaligenes xylosoxicans degrading 2,2 dichloropropionate and horizontal transfer of its halidohydrolase gene in a soil microcosm, Curr. Microbiol. 22 (1991) 299-306.

[69] W. Dejonghe, J. Goris, S. El Fantroussi, M. Hofte, P. De Vos, W. Verstraete E.M. Top, Effect of dissemination of 2,4-dichlorophenoxyacetic acid $(2,4-$ D) degradation plasmids on 2,4-D degradation and on bacterial community structure in two different soil horizons, Appl. Enivron. Microbiol. 66 (2000) 3297-3304 
[70] J. Kas, J. Burkard, K. Demnerova, J. Kostal, T. Macek, M. Mackova, J. Pazlarova, Perspectives in biodegradation of alkanes and PCBs, Pure Appl. Chem. 69 (1997) 2357-2369.

[71] L.P. Wackett, M.J. Sadowsky, L.M. Newman, H.G. Hur, S. Li, Metabolism of polyhalogenated compounds by a genetically engineered bacterium, Nature 368 (1994) 627-629.

[72] T.A. Anderson, B.T. Walton, Comparative fate of [14C] trichoroethylene in the root zone of plants from a former solvent disposal site, Environ. Toxicol. Chem. 12 (1996) 2041-2047.

[73] V.A. Nzengung, L.N. Wolfe, D.E. Rennels, S.C. McCutcheon, C. Wang, Use of aquatic plants and algae for decontamination of waters polluted with chlorinated alkanes, Int. J. Phytoremediation 1 (1999) 203-226.

[74] T.A. Anderson, E.A. Guthrie, B.T. Walton, Bioremediation in the rhizosphere: plant roots and associated microbes clean contaminated soil, Environ. Sci. Technol. 27 (1993) 2630-2636.

[75] R. Clemente, C. Almela, M.P. Bernal, A remediation strategy based on active phytoremediation followed by natural attenuation in a soil contaminated by pyrite waste, Environ. Pollut. 143 (2006) 397-406.

[76] S.T. Gregory, D. Shea, E. Guthrie-Nichols, Impact of vegetation on sedimentary organic matter composition and PAH attenuation, Environ. Sci. Technol. 39 (2005) 5285-5292.

[77] B.V. Aken, Transgenic plants for phytoremediation: helping nature to clean up environmental pollution, Trends Biotechnol. 26 (2008) 225227.

[78] D. Paquin, R. Ogoshi, S. Campbell, Q.X. Li, Bench-scale phytoremediation of polycyclic aromatic hydrocarbon-contaminated marine sediment with tropical plants, Int. J. Pytoremediation 4 (2002) 297-313.
[79] P. Vervaeke, S. Luyssaert, J. Mertens, E. Meers, F.M.G. Tack, N. Lust, Phytoremediation prospects of willow stands on contaminated sediment: a field trial, Environ. Pollut. 126 (2003) 275-282.

[80] R.F. King, A. Royle, P.D. Putwain, N.M. Dickinson, Changing contaminant mobility in a dredged canal sediment during a three-year phytoremediation trial, Environ. Pollut. 143 (2006) 318-326.

[81] K.E. Smith, A.P. Schwab, M.K. Banks, Phytoremediation of polychlorinated biphenyl (PCB)-contaminated sediment: a greenhouse feasibility study, J. Environ. Qual. 36 (2007) 239-244.

[82] T. Yamamoto, I. Goto, O. Kawaguchi, K. Minagawa, E. Ariyoshi, O. Matsuda, Phytoremediation of shallow organically enriched marine sediments using benthic microalgae, Mar. Pollut. Bull. 57 (2008) 108-115.

[83] M. Zarull, J. Hartig, L. Maynard, Ecological Benefits of Contaminated Sediment Remediation in the Great Lakes Basin, Sediment Priority Action Committee, Great Lakes Water Quality Board, 1999, www.ijc.org.

[84] US-EPA, Assessment and Remediation of Contaminated Sediments (ARCS) Program, Remediation Guidance Document EPA 905-B94-003, 1994 http://epa.gov/glnpo/arcs/EPA-905-B94-003/B94-003.ch3.html.

[85] H. Ballerstedt, A. Kraus, U. Lechner, Reductive dechlorination of 1,2,3,4 tetrachlorodibenzo-p-dioxin and its products by anaerobic mixed cultures from Saale River sediment, Environ. Sci. Technol. 31 (1997) 1749-1753.

[86] D. Ellis, E. Lutz, J. Odom, C. Buchanan, M. Lee, M. Harkness, K.A. DeWeerd, Bioaugmentation for accelerated in situ anaerobic bioremediation, Environ. Sci. Technol. 34 (2000) 2254-2260.

[87] C. Gomez-Hermosillo, J. Pardue, D. Reible, Wetland plant uptake of desorptionresistant organic compounds from sediments, Environ. Sci. Technol. 40 (2006) 3229-3236. 